\title{
Learners' Conceptual Understanding about Image Formation by a Convex Lens: How and to What Extent Can it be improved?
}

\author{
M. John, J.M. Molepo, M. Chirwa \\ Walter Sisulu University \\ South Africa
}

\begin{abstract}
The research conducted for this paper evaluates the effectiveness of an interactive optics teaching module, designed to enhance conceptual understanding by adopting a quasi-experimental pre-test - post-test design. One intact Grade 11 class in a selected school was chosen as the experimental group $(N=36)$ and another intact Grade 11 class in the same school was chosen as the comparison group $(N=44)$. The data were collected from four relevant questions of a 4-tier Optics Diagnostic Instrument (4ODI), which was designed for the larger version of the study. Even though there were 4 tiers for each question of the $4 O D I$, this paper reports only on the data collected from the participants' responses to the $1^{\text {st }}$ (answer tier) and the $3^{\text {rd }}$ tier (reason tier) of each of the four questions. The findings suggest that the practical experiment, supported by carefully-designed worksheets, worked significantly better than the computer simulation in improving learners, conceptual understanding of image formation by lenses. The main contribution of this study lies in its authenticity in advocating that Physics education researchers and educators need to integrate technology and practical experiments appropriately into the traditional worksheet-based learning and teaching activities. Furthermore, the study recommends that practical experiments, if properly designed and implemented, can act as an effective approach to science teaching and learning.
\end{abstract}

\section{Introduction}

Children come to classroom holding a variety of intuitive ideas resulting from their daily-life experiences; these ideas play a significant role in their learning experiences in the classroom. For the teaching-learning process to be more meaningful, it is necessary to understand how scientific concepts are distorted and accommodated by the learners [1]. If educators have an idea about the prior knowledge held by their learners, it can pave the way towards adopting effective teaching strategies for a better conceptual understanding of scientific concepts. The traditional instructional methods can then be replaced by more effective instructional approaches which can challenge learners with qualitative questions that cannot be answered through memorization and which help them learn how to respond to such questions [2].

Even though Mathematics, Science and Technology (MST) education has been a national priority in South Africa for several years, the number of learners who pass Grade 12 remains very low [3]. The authors [3] further assert that the poor state of Mathematics and Science Education in South Africa can be attributed, in part, to many teachers' limited content knowledge, ineffective teaching approaches and unprofessional attitudes. This is supported by [4] who had categorized the existing teaching strategies amongst the factors which influence directly on the poor performance of South African learners in Mathematics and Physical Sciences. It was further reported by [4] that learners can be motivated towards the subject if educators are confident with respect to knowledge of the subjects they teach, have a grasp of common misconceptions learners present in the classroom, and possess strategies for inducing learners' conceptual change.

Many groups and organizations have tried to improve the state of school Mathematics and Science through a variety of interventions; however, most of these were short-term solutions, often only once-off attempts and had no theoretical foundation. If meaningful improvement in both the achievement and the quality learning of Physical Sciences is to be fulfilled, it is important to make the necessary changes in the teaching and learning methods of the subject. Without understanding where the problems and deficiencies lie, it is meaningless to change the teaching or learning methods, or even the curriculum. Educators and researchers need to know what explanations and intuitions the abundant experience of prior knowledge has generated in learners' minds because prior knowledge has a decisive effect on the outcome of the instruction. This is why it becomes important to study the way learners conceptualize the subject and what their conceptions in each knowledge area are; this information can then be used as the starting step to design appropriate conceptual change strategies. 


\section{The idea of conceptual change}

Several studies have shown that it can be difficult to convince a learner to give up a long-held conception unless the new concepts are more valid, more powerful and more useful [5]. According to [2], although some misconceptions may be addressed through standard instruction or gradually disappear as the course progresses, others are highly resistant to instruction and in some cases, these become sufficiently serious that they may impede, or even preclude, development of a functional understanding. Thus, if the learners continue their formal schooling with a faulty understanding of the scientific phenomena, it may hinder meaningful learning, not only at the school level, but also in all the advanced levels of their studies.

From the research over the past two decades, science educators began to accept the fact that learners needed to discard some prior knowledge or alternative conceptions and were required to experience conceptual change in order for teaching and learning to be effective [6]. As a result, different approaches were proposed aiming at attaining the conceptual change of learners regarding many scientific phenomena.

According to [7], accommodation of a concept is the key factor responsible for conceptual change. They suggest four conditions which must be fulfilled before any accommodation is likely to occur. These are given below:

1. There must be dissatisfaction with existing conceptions.

1. Individuals must lose faith in the capacity of their current concepts to solve the problems they encounter.

2. A new conception must be intelligible.

3. A new conception must appear initially plausible.

This means that accommodation must at least have the capacity to solve the problems generated by its predecessors.

4. A new concept should suggest the possibility of a fruitful research programme.

Some methods to attain these conditions are suggested by [6]: to achieve the conditions, science educators can use discrepant events which can contextualize learners' prior knowledge and cause a cognitive condition. A new conception can be made intelligible by methods such as observations in authentic activities, cognitive apprenticeship under science educators and collaboration with learning peers.

The conceptual change model proposed by [7] has been criticized by other researchers [8]. They view Posner's model as promoting a confrontresolve-replace approach to instruction, where learners' misconceptions are confronted with discrepant events and they are given the opportunity to replace their misconceptions with the more useful concept. They point out that instructions that rely on this model may fall short in recognizing the value of learners' ideas for further instruction. While assessing prior knowledge, the educator must be flexible in such a way that the valuable experience-based concepts that, learners bring to a situation and the meanings that learners attribute to the formal language, are taken into consideration rather than limiting the assessment tasks to access only whether or not learners are able to state sentences that sound correct.

\section{Image formation by a convex lens}

Optics is such a scientific area in which children are exposed to a lot of experiences in their every-day lives. When learners' conceptions vary from the currently-accepted scientific point of view, these conceptions are frequently termed "misconceptions"; but according to the constructivist view, the ideas that learners hold make more sense to them than the corresponding scientifically-accepted conceptions which makes the term "alternative conceptions" more appropriate than the term "misconceptions". Traditional instructions are not very effective in overcoming certain conceptual difficulties [2]. Learners strongly support their conceptions with the help of different arguments such as experiences from their daily lives, the incorrect ideas they perceived from their textbooks, previous teachers, peers, elders and so on.

\subsection{Learners' prior knowledge}

[9] explained that physicists use a 'point-topoint mapping model' whereas the most prevalent conceptions held by learners are based on the 'holistic model' and the 'pin-hole model'. In the point-to-point mapping model, an extended object is considered as an assembly of object points and each point on the object has a corresponding image point after the cone of diverging light rays is converged by the lens. The assembly of all the image points forms the image. In the holistic model, learners' conceptualization is that parallel light rays move through space from the object, turn upsidedown inside the lens and the screen blocks these rays to form an image on it. According to this model, if the position of the screen is changed, the clarity of the image is not affected and only the size is affected. In the pin-hole model, rays from the entire object converge at the optical centre of the lens. The lens, then diverges these light rays when they pass through it. Finally, the screen blocks these light rays to form the image of the entire object. The pre-test results and interviews taken before the alternative teaching intervention proved that many learners gave alternative answers/explanations to the questions regarding the image formation by a 
convex lens since they applied 'holistic conceptualizations' of image formation rather than the physicists' 'point-to-point mapping model [9]. The author assumed that the learners held such conceptions because of their study of the pin-hole camera and the formation of an inverted image by convex lenses in most cases.

The "classic diagram" which is traditionally used in the academic treatment of imaging with a converging lens as prone to impose many problems in understanding optics [10]. Some of these are listed below:

- An exclusive focusing on the "central ray" may lead to a notion that the point-to-point correspondence is ensured by one ray only, and the image is not localised.

- Consideration of only two rays (central ray and a ray parallel to the principal axis and passing through the focal point after refraction) may lead learners to think that if these rays are blocked, the image disappears totally.

- The classic diagram also encourages the idea of a "travelling image" or its variants.

The experiments using the classic experimental device, like an optical bench, were also considered to convey some misunderstandings since the horizontal direction is privileged in the experimental set up. Some common expressions used in teaching and discussion may also be misinterpreted by the learners. To cite an instance, the authors point out that the common expressions like, "the image is received on a screen" may give learners the erroneous idea that an image is a kind of copy that travels in space like an ordinary object and reaches the screen after undergoing some limited transformations.

\subsection{Conceptual change strategies}

Amongst various conceptual change approaches found in the literature, computers were found to be widely used to enhance the conceptual understanding of various topics in science in general, and optics, in particular. Some examples are optics dynagrams [11] which is the short form for dynamic diagrams (an interactive learning environment), the RAY learning environment, which includes a flexible ray-tracing simulation and other graphic tools, and converging lens simulation [12].

A computer-based collaborative learning instruction was found to have used by [9] to help learners understand the image formation by lenses in three stages (namely, pre-test, computer-based activity and post-test). In the first stage, some of the alternative conceptions held by the learners regarding image formation by lenses were identified. According to [12], the design of a computer simulation may determine its potential for influencing the conceptual development and understanding of a learner. Their study examined the effects of four differently-designed simulations on learners' predictions and subsequent understanding. The study concentrated on how images are formed by converging lenses, specifically in relation to outcomes when portions of the lens or object are covered. The parameters involved in these simulations, such as focal length of the lens and the object's size and location, could be quickly varied in order to observe the resulting effects on image properties. Varying the number of rays depicted in the computer simulation was found to have no definite effect on learners' predictions of image formation as portions of the lens or object were covered. Moreover, it did not affect learners' explanations once the actual phenomenon was observed. However, learners' predictions of image formation as portions of the lens and object were covered were found to be affected by the origination point of the rays depicted in the simulation. The most important finding of the study was the significant impact of 'minimal instructor scaffolding' on the effectiveness of computer simulations.

\section{Theoretical framework}

Since traditional instructions are proved not to be very effective in overcoming certain conceptual difficulties [2], appropriate teaching modules must be designed and tested if they result in meaningful conceptual changes among the learners. Moreover, the design of any teaching module which aims at learners' conceptual change must start with the identification of prior knowledge. The present study was thus framed by incorporating the above ideas, most of which were proposed by [13]. According to this model, the educators must be able to diagnose their learners' thoughts on the topic in hand before designing any teaching strategy. The assessment of prior knowledge is therefore essential in inculcating meaningful conceptual change regarding any scientific concept.

The educators must take into consideration the assessed prior knowledge carefully in designing an appropriate teaching module for conceptual change. While designing the teaching module, it is important for the educators that they should give their learners provisions to clarify their thoughts to know if their conceptions are plausible or fruitful to explain different situations. The educators must also create situations where the learners become dissatisfied with their existing alternative conceptions. Moreover, the learners must be given opportunities for the desired view to be used in explaining a phenomenon. In addition, to help the learners accept their newly-acquired conceptions as fruitful, they must be given opportunities to apply these conceptions to different examples [13]. 


\section{Purpose of the study}

The focus of this paper is to dwell on learners' conceptual understanding of the image formation by a convex lens and to test how effective the designed conceptual change module was in promoting the participants' conceptual understanding about the topic.

\section{Methodology}

The study adopted a quasi-experimental design. One intact Grade 11 class in the selected school was chosen as the EG $(\mathrm{N}=26)$ and another intact Grade 11 class was chosen as the $\mathrm{CG}(\mathrm{N}=$ 44); the sample thus consisted of a total of 70 learners. The school was conveniently chosen as the research site because of its accessibility to the reseracher who was a full-time Physical Sciences educator in the same school (during the period when the research was conducted). Among the seven Grade 11 classes in the school, the selection of the two intact classes for the research was done on purpose (or purposive sampling was used in the selection of the participants) because these two classes were taught by the same educator and belonged to the same subject stream.

The data were collected from 4 relevant questions of the 4-tier Optics Diagnostic Instrument (4ODI), which was designed for the larger version of the study. However, the partcipants' responses to only the $1^{\text {st }}$ tier (answer tier) and the $3^{\text {rd }}$ tier (reason tier) of the four relevant questions are reported in this paper. The participants' responses to the second tier (confidence tier to the first tier) and those to the $4^{\text {th }}$ tier (confidence tier to the $3^{\text {rd }}$ tier) are not reported in this paper, the details of which can be seen in our previous work [14].

The $1^{\text {st }}$ tier is a content-based multiple choice question where the participants were asked to choose the correct answer from a given set of options; provisions were also provided in the cases where the participants would have answers which do not belong to the given options. To go deeper into the learners' conceptions regarding the image formation by a convex lens, each $3^{\text {rd }}$ tier question of the 4ODI was designed as an open-ended question which asked the learners to write reasons (reason tier) for their answer to the corresponding first tier. Instead of giving different pre-set alternatives as reasons as in previous studies [15] [16], in the present instrument, the respondents were allowed to write statements as reasons in order to capture a more in-depth understanding of the nature of conceptions/alternative conceptions held by the respondents.

In the 4ODI developed, the first tier was a quantitative form of data collection and the third tier moved to the details of the responses in the first tier, and hence collected the data qualitatively.
'Qualitative methods are more suitable when the research is also aimed at the meaning of particular events or circumstances. By making use of the 4ODI, the researcher could, thus, collect both quantitative and qualitative data regarding the participants' prior knowledge about the characteristics of the image formed by a convex lens. The summary of the key concepts tested in the 4 items of the questionnaire is given below:

Table 1. Key concepts tested in the questionnaire

\begin{tabular}{|c|c|}
\hline QN & Key concept \\
\hline 1 & Role of the screen in the image formation \\
\hline 2 & Role of the lens in the image formation \\
\hline 3 & $\begin{array}{c}\text { Image formed by a lens with a larger } \\
\text { diameter }\end{array}$ \\
\hline 4 & $\begin{array}{c}\text { Image formed when the upper half of the } \\
\text { lens is covered }\end{array}$ \\
\hline
\end{tabular}

After assessing the prior knowledge of the learners, the researchers designed a teaching module, which was meant to enhance the learners' conceptual understanding of the characteristics of the image formed by a convex lens. The teaching module mainly consisted of the following parts:

1. A practical investigation using an optic bench supported by a properly-sequenced worksheet; and

2. A converging lens computer simulation [13], supported by a properly-sequenced worksheet.

The designed optics teaching module therefore consisted of multiple teaching approaches integrated into a proper sequential order. While integrating different approaches, the researchers intended to fill up the gaps which might have been created by the use of just one method alone. Even though the researchers borrowed the works of some other researchers and educational practitioners (especially the computer simulations), the researchers took great care to integrate these works from the others properly with the researcher's own works (such as the worksheets for each activity).

The researchers implemented the designed optics teaching module only when teaching the EG; and the $\mathrm{CG}$ was taught using the traditional teaching method. Soon after implementing the teaching module, the researchers then administered the PoT using the same 4ODI previously used for the PrT.

\section{Findings}

The mixed-method approach used in the study explored several alternative conceptions the learners had held in terms of the roles that the lens and the screen play in the image formations and the characteristics of the image formed when a lens with a larger diameter is used and when a portion of the lens is covered. The effectiveness of the 
designed teaching module was tested by comparing the participants' responses in the pre-test and in the post-test.

\subsection{Findings from Tier 1 responses}

The responses of the participants from both the EG and the CG to the first tiers of the questionnaire (for both the PrT and the PoT) are presented in Table 2. In Table 2, scientifically-accepted responses are indicated in bold letters. It was noted that the participants from both EG and CG displayed correct understanding about the role of the lens in the image formation (Question 2) before and after the teaching module was implemented. However, the PrT results showed that the participants in both the groups were found to have a poor understanding of the concepts tested in all the remaining three questions. Amongst the different responses, some of the major alternative conceptions identified from the participants' Tier 1 responses of the PrT are listed below:

- In the absence of a screen, no image will be formed (Question 1);

- When a lens with a larger diameter is used, the size of the image formed increases (Question 3); and

- When the upper half of the lens is covered, the upper half of the image disappears.

Table 2: PrT vs PoT comparison (Tier 1 responses) of the EG and the CG

\begin{tabular}{|c|c|c|c|c|c|}
\hline \multirow{2}{*}{ QN } & \multirow{2}{*}{ Response } & \multicolumn{2}{|c|}{$E G(n=26)$} & \multicolumn{2}{|c|}{ CG $(n=44)$} \\
\hline & & PrT & PoT & PrT & PoT \\
\hline \multirow[t]{7}{*}{1} & No image is formed & 23 & 15 & 32 & 33 \\
\hline & An upside (inverted) image is formed & 0 & 0 & 2 & 3 \\
\hline & The size of the image will increase & 0 & 0 & 0 & 3 \\
\hline & The size of the image will decrease & 0 & 0 & 2 & 1 \\
\hline & The brightness of the image will increase & 0 & 0 & 1 & 1 \\
\hline & The brightness of the image will decrease & 1 & 0 & 4 & 2 \\
\hline & Others & 2 & 11 & 3 & 1 \\
\hline \multirow[t]{8}{*}{2} & No image is formed & 20 & 21 & 35 & 28 \\
\hline & An upside (inverted) image is formed & 1 & 1 & 1 & 3 \\
\hline & An upright (erect) image is formed & 2 & 1 & 2 & 0 \\
\hline & The size of the image will increase & 0 & 0 & 0 & 1 \\
\hline & The size of the image will decrease & 1 & 0 & 0 & 0 \\
\hline & The brightness of the image will increase & 0 & 1 & 0 & 1 \\
\hline & The brightness of the image will decrease & 1 & 1 & 3 & 5 \\
\hline & Other answers & 1 & 1 & 3 & 6 \\
\hline \multirow[t]{8}{*}{3} & No image is formed & 1 & 1 & 0 & 1 \\
\hline & An upside (inverted) image is formed & 3 & 1 & 2 & 3 \\
\hline & An upright (erect) image is formed & 0 & 0 & 2 & 2 \\
\hline & The size of the image will increase & 9 & 4 & 18 & 19 \\
\hline & The size of the image will decrease & 3 & 4 & 3 & 2 \\
\hline & $\begin{array}{l}\text { The brightness of the image will } \\
\text { increase }\end{array}$ & 2 & 5 & 3 & 4 \\
\hline & The brightness of the image will decrease & 0 & 2 & 1 & 1 \\
\hline & Other answers & 8 & 9 & 15 & 12 \\
\hline \multirow[t]{6}{*}{4} & No image is formed & 2 & 1 & 4 & 3 \\
\hline & The upper half of the image will disappear & 17 & 5 & 29 & 34 \\
\hline & The lower half of the image will disappear & 5 & 1 & 5 & 6 \\
\hline & The brightness of the image will increase & 0 & 1 & 1 & 0 \\
\hline & $\begin{array}{l}\text { The brightness of the image will } \\
\text { decrease }\end{array}$ & 0 & 15 & 1 & 1 \\
\hline & Other answers & 2 & 3 & 4 & 0 \\
\hline
\end{tabular}

The PoT results showed dramatic improvement for the EG learners, especially in two aspects represented by Questions 1 and 4. This is evident in Chart 1 which shows the percentage of the correct responses of the EG and CG during the PrT and PoT. The EG learners performed well both in the
PrT and PoT in Question 2. On the other hand, even though the CG performed better than the EG in Question 2 in the PrT, their performance dropped slightly in the PoT. The performance in Question 3 remained poor for both groups on both occasions. 


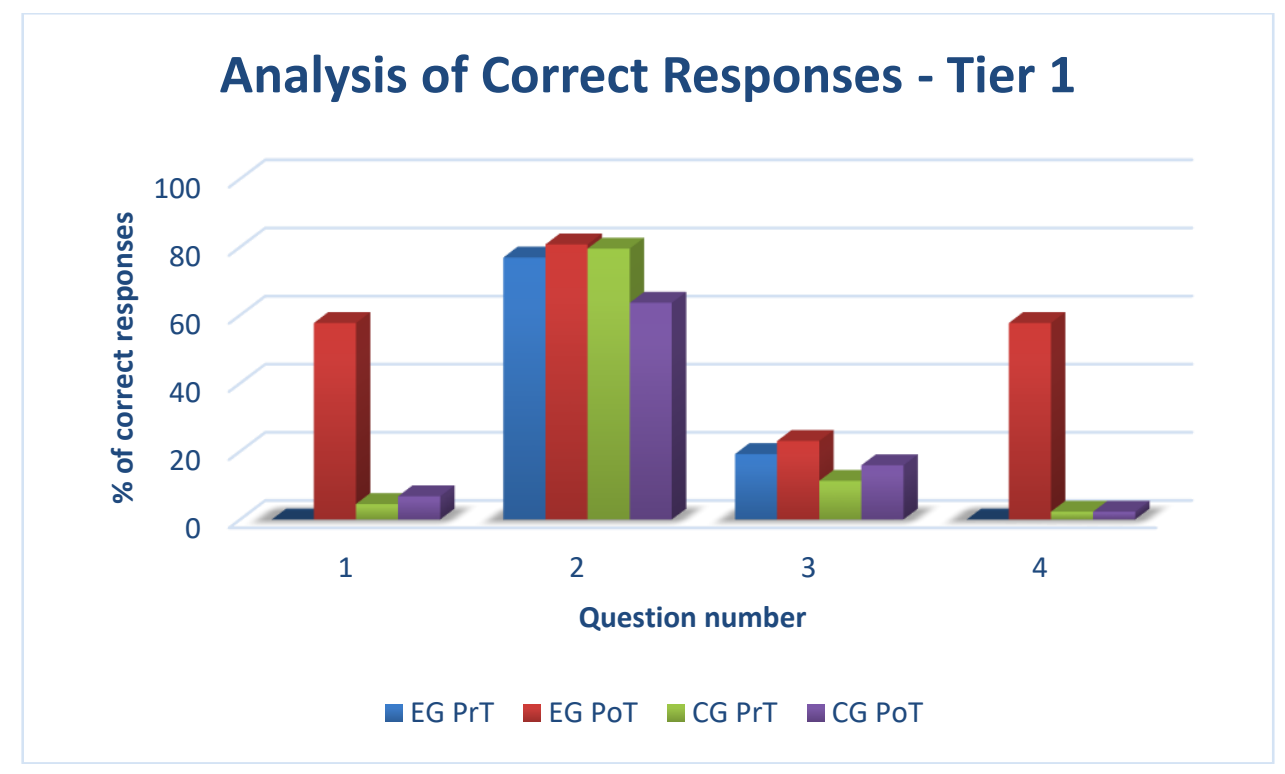

Figure 1. Analysis of Correct Responses - Tier 1

\subsection{Findings from Tier 3 responses}

Since Tier 3 of each question asked the learners to write reasons (in their own words) for their corresponding Tier 1 answers, the Tier 3 responses were analyzed qualitatively by reading and rereading the explanations given by the participants. The responses were then coded as Incorrect Responses, Incomplete Responses and Correct Responses, using the codes ICR, INCR and CR respectively. However, a more detailed picture of the analysis of the qualitative responses in this regard can be found in our previous work [17]. To obtain a brief picture of the extent to which the participants succeeded in justifying their answers to Tier 1 questions with scientifically-accepted explanations, a bar chart was used to present the analysis of the correct responses given by the participants (both the EG and the CG) during both the PrT and the PoT (please see Figure 2).

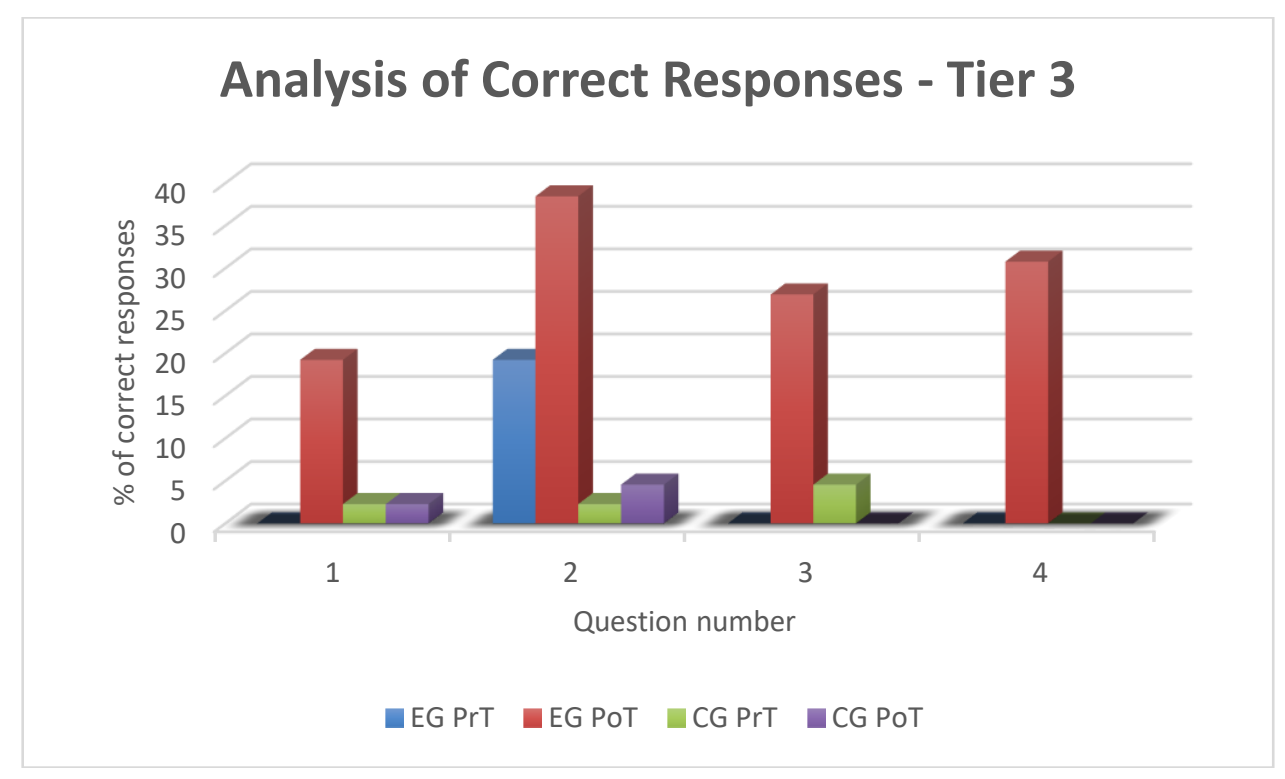

Figure 2. Analysis of Correct Responses - Tier 3

It was noted from Figure 2 that, the participants in both the groups did not succeed effectively in giving scientifically-accepted explanations (Tier 3) when they were asked to justify their Tier 1 responses during the PrT. However, the EG showed significant improvement in their PoT (in comparison to their PrT performance) in presenting scientifically-acceptable arguments as part of their Tier 3 responses. Nevertheless, the performance of 
the CG remained very poor in both the PrT and the PoT as far as their Tier 3 responses are concerned.

\section{Discussion of the findings}

To evaluate the effectiveness of the designed teaching module in improving secondary school learners' conceptual understanding of the characteristics of the image formed by a convex lens, the current study incorporated a quasiexperimental research design. The two-tier optics diagnostic instrument used to collect the data before and after the implementation of the teaching module was designed in such a way as to collect both quantitative and qualitative data.

\subsection{Discussion of the findings based on Tier 1 responses}

The data collected from the participants' responses from the first tiers of the questionnaire suggest that the designed teaching module can be considered to be successful in enhancing learners' conceptual understanding regarding certain characteristics of the image formed by a convex/converging lens. The PrT results showed that the participants from both the EG and the CG had a variety of alternative conceptions about the concept of image formation by a convex lens. There were many learners who strongly believed that when a lens of larger diameter is used, the size of the image increases without a change in brightness. It was identified that a large majority of the learners from both groups strongly believed that without a screen, a convex lens cannot form an image. This finding was found to be consistent with that of [9] in which the respondents claimed that without a screen, the image cannot be seen.

The number of learners who strongly believed that the upper half of the image disappears when the upper half of the lens is covered was very high. This was also found in agreement with the previous studies [18] [19].

The findings reported in this study, combined with similar findings from the previous literature (as listed above) suggest that the image formation by a convex lens has been an area in which learners experience many conceptual difficulties. This has been so for many years and in many parts of the world.

The findings emerged from the PoT indicated that the first part of the teaching module was effective in correcting learners' alternative conceptions (Questions 1,2 and 4); however, the second part of the teaching module was not much effective in doing so. Several attempts ave been made by previous researchers to improve learners' conceptual understanding regarding the optical phenomena. Some of them have been collaborative learning mediated by multimedia, computer- assisted learning programs [9], converging lens simulations [12] and conceptual change texts [20].

Computer-assisted learning programs were used to enhance learners' conceptual understanding regarding image formation by convex lenses [9]. It was claimed that such an approach was particularly helpful to students who were comfortable with peer collaboration and were prepared to engage intensively in the learning tasks (and with each other) and tried to test out their ideas on the multimedia CAL programs. A similar approach was tried by [12] focusing on the same topic, that is, image formation by convex lenses. The authors integrated computer simulations into their instructional practices and examined the effects of different simulations on students' predictions and subsequent understanding of how images are formed by converging lenses, specifically in relation to outcomes when portions of the lens or the object are covered. Their results indicate that changing the number of rays (depicted in the lens simulations) had little effect on student predictions, but the point (s) of origin of the rays did influence student predictions.

To eliminate misconceptions about "propagation of light", "reflection of light" and "refraction of light", [20] prepared conceptual change texts. Through a quasi-experimental approach, the study showed that the conceptual change texts were more effective than the traditional method of instruction in eliminating learners' misconceptions about geometric optics.

The current study is in agreement with the previous literature in that conceptual change texts (similar to the sequentially-arranged worksheets in the present study) and practical experiments supported by such worksheets can work effectively in the remediation of alternative conceptions/misconceptions; however, the computer simulations did not work well in improving learners' conceptual understanding of the image formation by convex lenses.

\subsection{Discussion of the findings based on Tier 3 responses}

It is evident from the findings that the designed teaching module helped in developing a deep conceptual understanding amongst the EG learners. The learners did, not only present the correct answers to the questions of the PoT, but they also succeeded in justifying their answers using scientifically-acceptable arguments. Such an evaluation would not have been possible if the researchers had used multiple-choice questionnaire as the data collection instrument. Thus, apart from the increase in the number correct responses to different questions, more effective attempts at justifying those correct responses with scientifically-acceptable arguments were identified 
in the PoT. The EG learners were therefore found to have gained a clearer conceptual understanding during the PoT than during the PrT.

Instead of giving pre-set options in the second tier as in the traditional two-tier multiple-choice type questionnaires [15], the learners were given the freedom to respond, in their own words to the reason tier of the 4ODI by answering an openended question. The advantage of using such an open-ended question in the $3^{\text {rd }}$ tier is that the researchers did not delimit the conceptions of the learners by giving pre-set options. The use of the open-ended third tier could capture some of the advantages of the interviews because the learners had first been given an opportunity to present their answer or choose their answer from among the given options, and, secondly, to explain their answers in their own words. Thus, by the use of open-ended questions in the $3^{\text {rd }}$ tier of each question of the 4ODI, and analysing qualitatively the learners' responses, the researchers could obtain an in-depth understanding of the learners concecptions/alternative conceptions.

The analysis of the learners' responses to the $3^{\text {rd }}$ tiers of the PrT revealed that even though the learners' responses to some questions were incorrect, the arguments presented by some of these learners were scientifically acceptable. This might be an indication of the weak understanding of certain scientific concepts and of the lack of ability to apply the scientific conceptions correctly to different situations. Such situations were identified when the learners used scientifically-acceptable arguments to support the incorrect answers in Question 3 of the PrT. For example, a few learners from both the groups believed that when a larger lens is used, more light rays will be refracted. Even though the above argument is scientifically acceptable, it was noted that the learners failed to understand that it is the brightness of the image which is affected when more light rays are refracted and not the size of the image.

The explanations given by the participants indicated that some learners were confused about certain terminologies in optics, such as, reflection and refraction. Participants from both the groups were found to have used the terms reflection instead of refraction to explain the image formation by a convex lens; this happened more often during the PrT with the EG than during the PoT. This reminds educators the importance of implementing careful strategies in optics classrooms when dealing with closely-related science concepts such as reflection and refraction.

\section{Conclusion}

Our research paper explores South African Grade 11 learners' conceptual understanding of the image formation by a convex lens and then evaluates the effectiveness of the designed optics teaching module in improving learners' conceptual understanding of the topic. The use of 4ODI enabled the researchers to collect both the quantitative and qualitative data simultaneously. The mixed-method mode of data collection employed in the 4ODI (using the $1^{\text {st }}$ tier as the quantitative and the $3^{\text {rd }}$ tier as the qualitative) helped the researchers to go deeper into the learners' conceptual understanding of the image formation by a convex lens. Moreover, the quasiexperimental research design adopted in this study helped the researchers to compare the designed teaching module with the traditional teaching module by administering PrT and PoT to both the EG and the CG.

The findings that emerged from this study suggest that the participants had a variety of alternative conceptions regarding the characteristics of the image formed a convex lens. However, a variety of teaching strategies such as worksheets and laboratory experiment, when carefully integrated, could improve learners' conceptual understanding of converging lens image formation. The hands-on and real-life experience which made possible in the laboratory experiments still dominate over modern technologies such as computer simulations in bringing about meaningful conceptual change among science learners. The findings from this study thus point to the importance of integrating practical experiments properly in the science learning and teaching process. In short, the optics bench practical experiment supported by the sequentially-arranged worksheets was found to be more successful in improving learners' conceptual understanding of image formation by lenses than the converging lens computer simulation (even though it was also supported by worksheets of a similar nature).

\section{References}

[1] Lin, H., Cheng, H. \& Lawrenz, F. (2000) 'The assessment of students and teachers' understanding of gas laws', Journal of Chemical Education, 77 (2), p. 235 .

[2] McDermott, L. C. (2001) 'Oersted Medal Lecture 2001: Physics Education Research - The Key to Student Learning', American Journal of Physics, 69, pp. 1127-1137.

[3] Kriek, J. \& Grayson, D. (2009) 'A holistic professional development model for south african physical science teachers', South African journal of education, 29 (2), pp. 185-203.

[4] Mji, A. \& Makgato, M. (2006) 'Factors associated with high school learners' poor performance: a spotlight on mathematics and physical science', South African journal of education, 26 (2), pp. 253266. 
[5] White, R. \& Gunstone, R. (1989) 'Metalearning and conceptual change', International Journal of Science Education, 11, pp. 577-586.

[6] Tsai, C. (2001) 'The interpretation construction design model for teaching science and its applications to Internet-based instruction in Taiwan', International Journal of Educational Development, 21 (5), pp. 401-415.

[7] Posner, G., Strike, K., Hewson, P. \& Gertzog, W. (1982) 'Accommodation of a scientific conception: Toward a theory of conceptual change', Science Education, 66 (2), pp. 211-227.

[8] Otero, V. \& Nathan, M. (2008) 'Preservice elementary teachers' views of their students' prior knowledge of science', Journal of Research in Science Teaching, 45 (4), pp. 497-523.

[9] Tao, P. (2004) 'Developing understanding of image formation by lenses through collaborative learning mediated by multimedia computer-assisted learning programs', International Journal of Science Education, 26 (10), pp. 1171-97.

[10] Viennot, L. \& Kaminski, W. (2006) 'Can we evaluate the impact of a critical detail? The role of a type of diagram in understanding optical imaging', International Journal of Science Education, 28 (15), pp. 1867-85.

[11] Reiner, M., Pea, R. \& Shulman, D. (1995) 'Impact of simulator-based instruction on diagramming in geometrical optics by introductory physics students', Journal of Science Education and Technology, 4 (3), pp. 199-226.

[12] Bryan, J. \& Slough, S. (2009) 'Converging lens simulation design and image predictions', Physics Education, 44, pp. 264-275.

[13] Hewson, P. W. \& Hewson, M. G. A. (1988) 'Appropriate conception of teaching science: A view from studies of science learning', Science Education, 72 (50), pp. 597-614.

[14] John, M., Molepo, J. M. \& Chirwa, M. (2016) 'The Impact of an Interactive Ray Diagram Teaching Module in Enhancing Grade 11 Learners' Conceptual Understanding of Image Formation in a Plane Mirror', Eurasia Journal of Mathematics, Science and Technology Education (ISI accredited international journal). 12(3), pp. 637-653.

[15] Chen, C., Lin, H. \& Lin, M. (2002) 'Developing a two-tier diagnostic instrument to assess high school students' understanding - The formation of images by a plane mirror', Proceedings of National Science Council ROC (D), 12, pp. 106-121.

[16] Caleon, I. S. \& Subramaniam, R. (2010) 'Do Students Know What They Know and What They Don't Know? Using a Four-Tier Diagnostic Test to Assess the Nature of Students' Alternative
Conceptions', Research in Science Education, 40, pp. 313-337.

[17] John, M., Molepo, J. M. \& Chirwa, M. (2016) 'South African Learners' Conceptual Understanding about Image Formation by Lenses', Eurasia Journal of Mathematics, Science ad Technology Education, 13(6), pp. 1723-1736.

[18] Fetherstonhaugh, A. (1990) 'Misconceptions and light: A curriculum approach', Research in Science Education, 20 (1), pp. 105-113.

[19] Galili, I. \& Hazan, A. (2000) 'Learners' knowledge in optics: interpretation, structure and analysis', International Journal of Science Education, 22 (1), pp. 57-88.

[20] Aydin, S. (2012) 'Remediation of Misconceptions about Geometric Optics Using Conceptual Change Texts', Journal Of Education Research And Behavioral Sciences, 1 (1), pp. 001-012. 